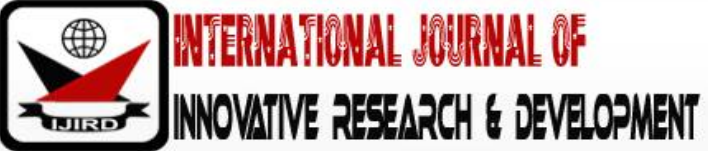

ISSN 2278 - 0211 (Online)

\section{Solvent-Free Synthesis and Evaluation of Antimicrobial Activity of Vanadium (III) Metal Complex Using Two Amino Acids as Mixed Ligands}

Mannir Muhammad
Academic Technologist, Department of Chemistry,
Umaru Musa Yar'adua University Katsina, Nigeria
Nura Suleiman Gwaram
Lecturer, Department of Chemistry,
Umaru Musa Yar'adua University Katsina, Nigeria
Jabiru Musa
Masters Student, Department of Chemistry,
Umaru Musa Yar'adua University Katsina, Nigeria

\begin{abstract}
:
Vanadium (III) metal complex was synthesized mechanochemically using L-Leucine and Creatinine as mixed ligands. The metal and the ligands were grinded using an agate mortar with pestle. The compound formed was characterized by melting/decomposition temperature, solubility test, magnetic susceptibility, conductivity measurement and Infrared analysis. The metal - ligand ratios were investigated via Job's method of continuous variation and revealed it to be 1: 1 in the metal complex. The shifts of bands (2959-3204 to 3327 in $v N-H$ ) and appearance of new bands (671 and 750$)$

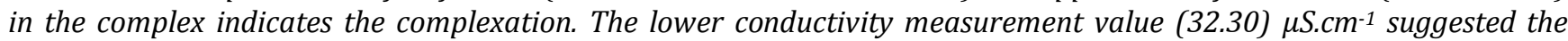
non-electrolytic nature of the complex. The magnetic effective value of the metal complex (3.83BM) showed that the complex is paramagnetic and octahedral. It was concluded that the amino acids (ligands) coordinated in a bidentate way through the nitrogen from amino group and oxygen from carboxylate. The complex was screened for its antimicrobial activities against two bacterial and one fungalisolate (Streptococcuspneumoniae, Klebsiellapneumoniae and Aspergillus Niger). The complex exhibited good activity against the organisms.
\end{abstract}

Keywords: Mechanochemistry, antimicrobial, metal complex, amino acids, mixed ligands, Grinding

\section{Introduction}

Sani and Lawal (2017) have investigated the solvent-assisted mechanochemical synthesis of a widely-used class of organic imine-based ligand. Specifically, diamine-type lig and which are formed from 2-hydroxy-1-naphthaldehyde and 1, 2- phenylenediamine under solvent assisted mechanochemical conditions. Similarly, two Co (II) complexes containing malonic and isonicotinic acids have been prepared by manual grinding of stoichiometric amounts of the starting materials. Elemental analysis (CHN), IR, UV-vis spectroscopic techniques, TGA-DTG investigation and X-ray powder diffraction analysis were used to characterize the two compounds. Isonicotinic acid coordinated to the metal via the pyridine ring nitrogen and one oxygen atom of the carboxylic group while malonic acid coordinated via both oxygen atoms of the carboxylate groups indicating bidentate coordination mode in the two compounds. The compounds were exposed to some volatile organic compounds (VOCs) containing nitrogen or oxygen donor atoms in the solid state and their vapochromic behaviors studied using color changes, FT-IR and solid-state UV-vis spectroscopies. Heating the samples exposed to the VOCs for a few minutes at $100^{\circ} \mathrm{C}$ regenerates the original material without degradation, even after several heating cycles (Tella et al. 2016).

The studies under the area of mechanochemistry, which cover the grinding chemistry, to ball milling, sonication etc., are certain of interest to the researchers working on the development of green methodologies (Achar, Bose and Mal, 2017). Mechanochemical synthesis emerged as the most advantageous, environmentally sound alternative to traditional routes for nanomaterial preparation with outstanding properties for advanced applications. (XU et al, 2015). Mechanochemical synthesis involves a reaction between dry reactants i.e. with no added liquid that might act as a solvent. However, some reactions in this type can result in the generation of liquid during the reaction. For example, when anyone of the reactants is a hydrate producing liquid water during the reaction or when liquid by products such as water or acetic acid are produced as condensates during the reaction (Friščić, 2012). 
Also, $\mathrm{Mn}(\mathrm{II}), \mathrm{Fe}(\mathrm{II}), \mathrm{Co}(\mathrm{II}), \mathrm{Ni}(\mathrm{II}), \mathrm{Cu}(\mathrm{II})$ and $\mathrm{Zn}(\mathrm{II})$ complexes of mixed ligands, Riboflavin (HL) and 4-aminobenzoic acid (HL1) were synthesized and characterized by percentage metal, infrared and electronic (solid reflectance) spectroscopies, room temperature magnetic moments, melting points and conductance measurements. The conductance measurements in DMSO and percentage metal analysis indicated that all the metal (II) complexes were covalent and analyzed as [M (HL) (HL1) X], where $\mathrm{X}=\mathrm{Cl} / \mathrm{SO}$. Infrared spectra data confirmed that coordination was via the 24 oxygen atoms of two hydroxyl groups in Riboflavin, and the carboxylate oxygen atoms in 4-aminobenzoic acid respectively. Furthermore, electronic spectra data indicated that all the metal (II) complexes adopted octahedral geometry; while room temperature magnetic moment measurements indicated spin-crossover, that is, high spin low spinoctahedral equilibrium for all the complexes with the exceptions of the $\mathrm{Cu}$ (II) and $\mathrm{Zn}$ (II) complexes. In-vitro antimicrobial activities of the metal (II)complexes, riboflavin and p-aminobenzoic acid against Escherichia spp, Proteus mirabilis, Streptococcus pyogenes, Candida albicans, Salmonella sp, Streptococcus sp, Bacillus spp, Staphylococcus sp and Pseudomonas spp revealed that all the metal (II) complexes and ligands were active against Pseudomonas sp with inhibitory zones range of 7.0-11.0 mm. The antioxidant studies on the metal complexes showed that the Zn (II) complex had the best antioxidant activity of about 62 percentage inhibition, which was about twice the percentage inhibition of the standards, ascorbic acid and D-tocopherol (Agbaje, Osowole, MalumiandWakil, 2015).

The aim of this paper is to synthesize, characterize and study the antimicrobial activities of Co (II), Ni (II) and V (III) metals of mixed ligands complexes of L-Leucine, L-Tyrosine and Creatinine by mechanochemical method.

\section{Materials and Methods}

\subsection{Materials}

All the chemicals were used as obtained without further purification. Most of the chemicals are of analytical grade. All the glass wares used in this work were washed with detergent and rinsed with distilled water and dried in an oven at 1100c.

All weighing was carried out using an electronic balance. The infrared spectral analysis was recorded using FTIR model vertex 70/70v. Conductivity measurement was done using conductivity meter (DDS-11) using DMSO as solvent. Melting point and decomposition temperatures were determined using Bamstead Electrothermal melting point apparatus IA9100. The proposed molecular structure of the complex was drawn by using chemsketch program ACD (2016). The antimicrobial screening was carried out in the microbiology laboratory, department of microbiology, Umaru Musa Yar'adua University Katsina. Nigeria.

\subsubsection{Methods Mechanochemical Synthesis of the Metal Complex}

The metal complex of V (III) was synthesized by grinding $5 \mathrm{mmol}$ of the metal salts (VCl3) plus $5 \mathrm{mmol}$ of L-leucine and $5 \mathrm{mmol}$ of Creatinine in an agate mortar and pestle for 10-20 minutes which gave a crystalline powdered and was dried at 50 0C (Muhammad and Kurawa, 2019).

Mechanochemical synthesis of metal (III) complex

$\mathrm{Lcn} .+\mathrm{Crn}+\mathrm{MCl}_{3} \longrightarrow\left[\mathrm{M}(\mathrm{LCn})(\mathrm{Crn}) \mathrm{Cl}_{2}\right]$

Where: $\mathrm{M}=$ Metal $(\mathrm{V} 3+), \mathrm{Lcn}=\mathrm{L}-$ Leucine and $\mathrm{Crn}=$ Creatinine.

\subsection{Determination of Antimicrobial Activity}

The antimicrobial Activity against two bacterial and one fungal isolate (streptococcus pneumoniae, Klebsiella pneumoniae and Aspergillus Niger) was determined by the paper disc diffusion method.

\subsubsection{Media Preparation}

14g and 3.9g nutrient agar and potato dextrose agar were measured and dispersed in a conical flask containing distilled water agitated to dissolve, autoclaved at 1210c for 15 minutes (cheesbrough, 2006).

\subsubsection{Disc Preparation}

$6 \mathrm{~mm}$ disc were prepared using filter paper and sterilized before dispersing in to each of the tubes containing different concentrations of the complexes and ligands (CLSI, 2013).

\subsubsection{Preparation of Ligands and Complexes}

$0.2 \mathrm{~g}$ of each of the complexes was dissolved in $2 \mathrm{ml}$ of DMSO to obtain a concentration of $100 \mathrm{mg} / \mathrm{ml}$ followed by transferring to the next tube containing $1 \mathrm{ml}$ of DMSO to obtain another concentration of $50 \mathrm{mg} / \mathrm{ml}, 25 \mathrm{mg} / \mathrm{ml}$ and $12.5 \mathrm{mg} / \mathrm{ml}$.

\subsubsection{Disc Impregnation}

Disc containing different concentrations of each complex was transferred and dispersed in the Petri-dish containing Nutrient agar and potato dextrose agar with the suspension of Klebsiella pneumoniae, Streptococcus pneumoniae and Aspergillus niger strain and allowed to observed for 15-20 minutes, and then incubated at 370c for 24 hours and 72 hours for Aspergillus niger. 


\subsubsection{Measurement of Zone}

Prior to the incubation, zone of inhibition produced by the complex and the ligands was measured and recorded in millimetre using a meter ruler.

\section{Result and Discussion}

The results obtained from Table 1 and 2 show some physicochemical properties of the ligands and the complex.

The metal complex ofV (III) with L-leucine and Creatinine was synthesized.

The complex was prepared by grinding the metal salt with the ligands using 5:5 mole ratios, which means five mmole of the metal salt: five mmole of each of the ligands. The metal salt reacted with the ligands by mechanochemical synthesis and produced solid complex. The colour of the ligands and the metal complex are white powder and off-white crystals for L-leucine and Creatinine respectively while, that of metal complex was light green for the complex of V (III). The melting point of the ligands are 331and $3000 \mathrm{c}$ for L-Leucine and Creatinine respectively. The melting/decomposition temperature is 2470 c for V (III) metal complex. The melting/decomposition temperature of V (III) complex is lower than that of the ligands. This is probably because of its lower thermal stability that may be related to its structure [V (Lcn)(Crn)Cl2] (Gurbuz, Cinarli, Tavman and Tan, 2015).

The molar conductance of the complex in DMSO found to be in a lower value (32.3) $\mu \mathrm{S} . \mathrm{cm}-1$ supporting the nonelectrolytic behaviour of the complex (Al-noor and Abdulkarim, 2015). The ligands and the complex are insoluble in most common organic solvents such as chloroform, ethanol, methanol and n-hexane but they are relatively soluble in Dimethyl sulfoxide and Dimethyl formamide except a few of them which are either insoluble or slightly soluble. They are all slightly soluble in water as shown in Table 2.

The complex is paramagnetic with magnetic effective value of $3.83 \mathrm{BM}$. This value is in the range of octahedral geometry of complexes (Aurora et al.2009)

\begin{tabular}{|c|c|c|c|c|c|c|c|}
\hline Compound & Color & Yield\% & $\begin{array}{c}\text { M.Wt } \\
\text { Calc. }\end{array}$ & $\begin{array}{c}\text { Melting } \\
\text { point }{ }^{\text {OC }}\end{array}$ & $\begin{array}{c}\text { Decomposition } \\
\text { Temperature }\end{array}$ & $\boldsymbol{\mu}_{\text {eff }}$ (BM) & $\begin{array}{c}\text { Molar } \\
\text { conductivity } \\
\boldsymbol{\mu} \text { S.cm }^{\mathbf{1}}\end{array}$ \\
\hline$\left(\mathrm{C}_{6} \mathrm{H}_{13} \mathrm{NO}_{2}\right)$ & White & - & 131.18 & 331 & - & - & - \\
\hline$\left(\mathrm{C}_{4} \mathrm{H}_{7} \mathrm{~N}_{3} \mathrm{O}\right)$ & White & - & 113.12 & 300 & - & - & - \\
\hline$\left[\mathrm{V}(\mathrm{Lcn})(\mathrm{crn}) \mathrm{Cl}_{2}\right]$ & $\begin{array}{c}\text { Light } \\
\text { Green }\end{array}$ & 78 & 365.24 & - & 247 & 3.83 & 32.30 \\
\hline
\end{tabular}

Table 1: Some Physicochemical Properties Of The Ligands And The Complex

\begin{tabular}{|c|c|c|c|c|c|c|c|}
\hline Compound & chloroform & E-OH & Water & M-OH & DMF & DMSO & n-hexane \\
\hline L-leucine & IS & IS & SS & IS & IS & IS & IS \\
\hline Creatinine & IS & IS & SS & IS & S & SS & IS \\
\hline V (III) Complex & IS & IS & SS & IS & SS & S & IS \\
\hline
\end{tabular}

Table 2: Solubility of the Ligands and the Metal Complex in Some Common Solvents

( $S$ = Soluble, $S S=$ Slightly Soluble, $I S=$ Insoluble)

The IR spectra of the ligands and the complex were listed in Table 3. The IR spectra of the complex were compared with those of the free ligands so as to determine the coordination sites that may involve/participate in the coordination. In the process of the comparison, it was found that the $\mathrm{v}(\mathrm{N}-\mathrm{H})$ stretching vibration in the two ligands was 2959 - 3242. However, these bands were shifted to higher wave numbers in the complex (3327) indicating the participation of the nitrogen atom from the amino substituents in the coordination of the metal ions with the ligands (Aiyelabola et al, 2017). Supporting this further, is the observed shift to lower wave number for the $\mathrm{v}(\mathrm{C}-\mathrm{N}$ ) stretching frequency from 1365 - 1399 in the ligands to $1346 \mathrm{~cm}-1$ upon complexation.

There were significant shifts in the $v(C=0)$ stretching frequency of the ligands $(1693-1677)$,

Which lowered to $1629 \mathrm{~cm}-1$ in the complex. This could be as a result of the involvement of carbonyl oxygen in the coordination.

The C - 0 stretching band of the ligands was seen at $1313-1316 \mathrm{~cm}-1$. These were got shifted to lower frequency (1246) in the complex, indicating deprotonation and coordination of the hydroxyl oxygen to the metal ion (Sani and Lawal, 2017).

The new bands at 750 and $671 \mathrm{~cm}-1$ in the spectra of the complex were assigned to $\mathrm{v} \mathrm{M}-\mathrm{O}$ and $\mathrm{v} \mathrm{M}-\mathrm{N}$ stretching vibration respectively (Abdul Qadir et al, 2014).

Hence, it is concluded that all the two ligands behave as bidentate free ligands in the complex and that the coordination takes place in the oxygen and nitrogen atoms. 


\begin{tabular}{|l|l|l|l|l|l|l|}
\hline Compound & $\begin{array}{l}v(\mathbf{N}-\mathbf{H}) \\
\mathrm{cm}^{-1}\end{array}$ & $\begin{array}{c}v(\mathbf{C}=\mathbf{0}) \\
\mathrm{cm}^{-1}\end{array}$ & $\begin{array}{c}v(\mathbf{C}-\mathbf{0}) \\
\mathrm{cm}^{-1}\end{array}$ & $\begin{array}{c}v(\mathbf{C}-\mathbf{N}) \\
\mathrm{cm}^{-1}\end{array}$ & $\begin{array}{c}v(\mathbf{M}-\mathbf{N}) \\
\mathrm{cm}^{-1}\end{array}$ & $\begin{array}{c}v(\mathbf{M}-\mathbf{0}) \\
\mathrm{cm}^{-1}\end{array}$ \\
\hline L-Leucine & 2959 & 1677 & 1316 & 1365 & - & - \\
\hline Creatinine & 3242 & 1693 & 1313 & 1399 & - & - \\
\hline V(III) Complex & 3327 & 1629 & 1246 & 1346 & 671 & 750 \\
\hline
\end{tabular}

Table 3: Showing Some Selected Vibrational Frequencies of Ligands and the Complex

The antimicrobial activity of free ligands and their complex was evaluated using the micro broth paper disc diffusion method towards two bacterial and one fungal isolate. The results were compared with those of Augmentin against the two bacteria and Ketoconazoleagainstthefungi. The antibacterial activity of the metal complex and free ligands wascarried out against Streptococcus pneumoniae, Klebsiella pneumoniae and Aspergillus Niger; the results were presented in Table 4, 5 and 6 and figure 1, 2 and 3. The study shows high activities at higher concentrations in each case and vice- versa. The result also revealed that the activity of the free ligands is more pronounced after complexation.

\begin{tabular}{|c|c|c|c|c|}
\hline Complexes/Ligands & $\mathbf{1 0 0} \mathbf{m g} / \mathbf{m l}$ & $\mathbf{5 0} \mathbf{~ m g} / \mathbf{m l}$ & $\mathbf{2 5} \mathbf{m g} / \mathbf{m l}$ & $\mathbf{1 2 . 5} \mathbf{~ m g} / \mathbf{m l}$ \\
\hline V (III) Complex & 20 & 15 & 14 & 9 \\
\hline Creatinine(ligand) & 12 & 10 & 10 & NA \\
\hline L-Leucine(ligand) & 14 & 10 & 8.5 & NA \\
\hline Control & 27 & & & \\
\hline
\end{tabular}

Table 4: Showing the Antibacterial Activity of the Ligands/Complex against Streptococcus Pneumonia

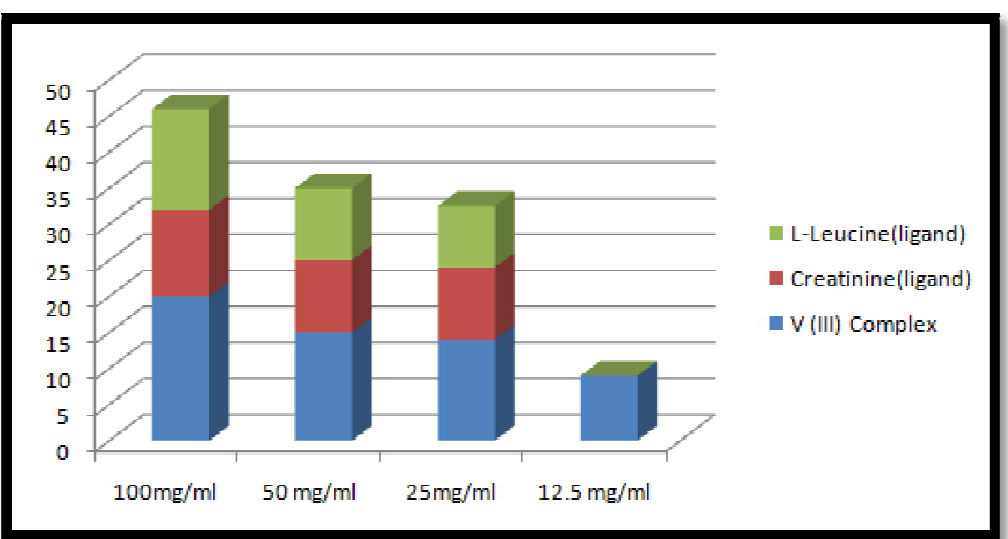

Figure 1: Showing the Antibacterial Activity of the Ligands/Complex against Streptococcus Pneumonia

\begin{tabular}{|c|c|c|c|c|}
\hline Complexes/Ligands & $\mathbf{1 0 0} \mathbf{m g} / \mathbf{m l}$ & $\mathbf{5 0} \mathbf{~ m g} / \mathbf{m l}$ & $\mathbf{2 5} \mathbf{m g} / \mathbf{m l}$ & $\mathbf{1 2 . 5} \mathbf{~ m g} / \mathbf{m l}$ \\
\hline V (III) Complex & 19 & 14 & 10 & NA \\
\hline Creatinine(ligand) & 8 & NA & NA & NA \\
\hline L-Leucine(ligand) & NA & NA & NA & NA \\
\hline Control & 24 & & & \\
\hline
\end{tabular}

Table 5: Showing the Antibacterial Activity of the Ligands/Complex against Klebsiella Pneumonia Key: NA = NO Activity Control = Augmentin

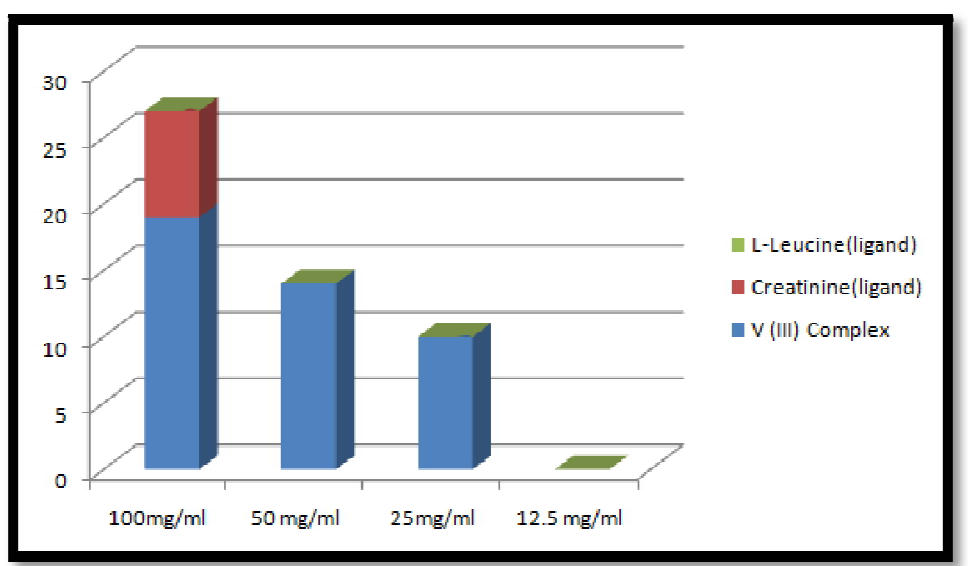

Figure 2: Showing the Antibacterial Activity of the Ligands/Complex against Klebsiella Pneumonia 


\begin{tabular}{|c|c|c|c|c|}
\hline Complexes/Ligands & $\mathbf{1 0 0} \mathbf{m g} / \mathbf{m l}$ & $\mathbf{5 0} \mathbf{~ m g} / \mathbf{m l}$ & $\mathbf{2 5 m g} / \mathbf{m l}$ & $\mathbf{1 2 . 5} \mathbf{~ m g} / \mathbf{m l}$ \\
\hline Vanadium (III) & 18 & 14 & 8 & NA \\
\hline Creatinine(ligand) & NA & NA & NA & NA \\
\hline L-Leucine(ligand) & NA & NA & NA & \\
\hline & & & & \\
\hline
\end{tabular}

Table 6: Showing the Antifungal Activity of the Complex/Ligands against Aspergillus Niger

Key

NA= Not Active

Control = Ketoconazole

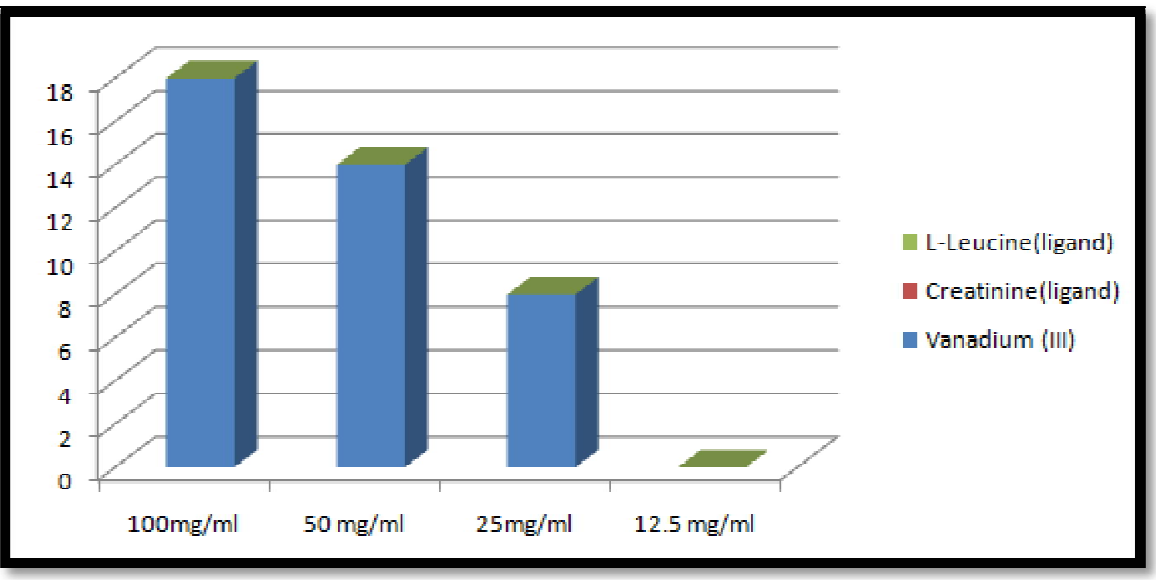

Figure 3: Showing the Antifungal Activity of the Complex/Ligands against Aspergillus Niger

\section{Conclusion}

V (III) complex of mixed ligands of L-Leucine and Creatinine was synthesized and characterized; the study shows that:

- The synthesized complex is non-electrolyte in nature.

- The two ligands behave as neutral bidentate that coordinate through 0 and $\mathrm{N}$.

- $\quad$ Both the ligands and the complex exhibited antimicrobial activity at varying degrees.

- The values showed that the ligands become more pronounced when coordinated to metal ion.

In conclusion, this complex that was synthesized from mixed ligands of amino acids could effectively be used for the treatment of some common diseases caused by streptococcuspneumoniae, Klebsiellapneumoniae and Aspergillusniger

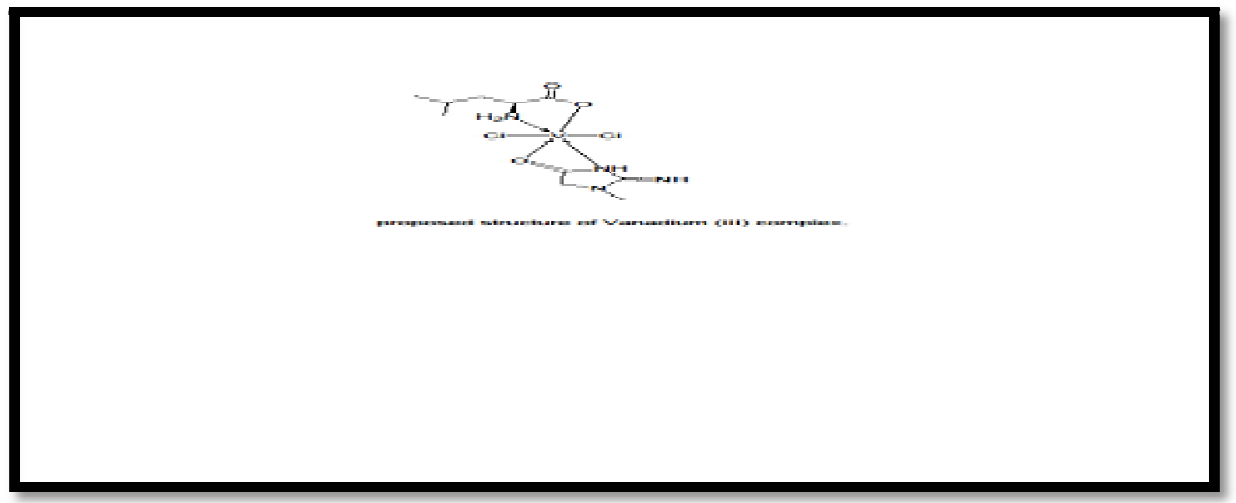

Figure 4: Proposed Molecular Structure of the Complex

\section{References}

i. C Tella, S. O Owalude, L. O Alimi, A. C Oladipo S.J Olatunji, O. G Adeyemi (2016): Facile Synthesis and Vapochromic Studies of Co (ii) complexes bearing 'NO' and 'OO' donor ligands: Egyptian Journal of basic and applied Sci 3: (2): $125-133$.

ii. Abdul Qadir M, Ahmad M, Ahmad A, Naz S, Azhar S, Khan R, Hussain R and Waseem R (2014). Synthesis of metal complexes with amino acids for Animal Nutrition. Research gate 12(6): 858-861.

iii. Achar Kumar Tapas, Anima Bose and Prasenjit Mal (2017): Mechanochemical Synthesis of Small Organic Molecules: Bilstein journal, org. chat 1(3):1907-1931.

iv. Agbaje O. Osowole A.A, Malumi; E.0 and Wakil SM (2015), Synthesis, spectroscopic characterization, antimicrobial and antioxidant properties of some metal (ii) complexes of mixed ligands - riboflavin and 4 - Aminobenzoic acid, research and review journal of chemistry. 14(2):1905 - 1933.

v. Aiyelabola T., Akinkunmi E., Obuotor E, Olawuni I, Isabirye D and Jordaan J (2017), Synthesis, characterization and Biological activities of coordination compounds of 4-Hydroxy-3-nitro-2H-chromen-2-one and its aminoethanoic 
acid and pyrrolidine-2-carboxilic acid mixed ligand complexes, Bioinorganic chemistry and Application. 10(1155):1-16.

vi. Al-noor T.H and Abdul Karim L.K (2015). Synthesis, characterization and Anti-Bacterial Activities of Co (II), Ni (II), $\mathrm{Cu}$ (II), Cd (II) and Hg (II) mixed ligand complexes of L-leucine and trimethoprim antibiotic: chemistry and material research: 7(3):32-39

vii. Aurora Reiss, Stelian Florea, Theodor Caprouio, Nicolae Stanica (2009), synthesis characterization and antibacterial activity of some transition metals with the Schiff base N-(2-furanyimethylene)-3-aminodibenzofuran, Turk J Chem. 33 (2009), 775 - 783.

viii. Cheesbrough M. (2006) District laboratory practice in tropical countries. Press syndicate publishers, University of Cambridge, Edinburgh Cambridge United Kingdom. 194 - 204.

ix. Friščić T. (2012): Supramolecular concept and new techniques Mechanochemistry: cocrystals, cages, rotaxanes, open, metal -organic frame work' chemical society reviews. 41: 3493-3510.

x. Gurbuz D, Cinarli A, Tavman A and Tan B.S (2015), Synthesis characterization and antimicrobial activity of some transition metal complexes of $\mathrm{N}$-(5-Chloro-2-hydroxyphenyl)-3-methoxy-salicyladimine; Chemical society of Ethiopia. 29(1): $63-74$.

xi. Muhammad M and Kurawa M.A (2019): 'solid state synthesize characterization and antimicrobial studies of Ni (11), Co (11), and $\mathrm{Cu}(11)$ complexes 1-(4-nitropheny1) imino] methy1) naphthalen-2-ol’ Chemsearch journal. 10 (1):38 -45

xii. Sani S and Lawal AM (2017): Liquid - assisted mechanochemical synthesis: green Approach to synthesis of Co (11) Schiff base complex and of antimicrobial activities' international journal of innovative research and development. 6(12)79-86

xiii. XU, C., De, s., Alina M., B., ojeda and lugues R (2015):'mechanochemical synthesis of advanced nanomaterials for catalytic application' royal society of chemistry. 51, 6698-6713. 